\title{
Execução Provisória de Sentença Condenatória Recontível
}

\author{
PAULO QUEZADO \\ Bacharel em Direito pela UFC. Advogado. \\ pauloquezado@pauloquezado.com.br
}

Sumário: 1) Introdução; 2) A Constituição como limite ao exercício do poder do estado; 3) A liberdade como regra e a prisão como medida excepcional: pilastras do estado democrático de Direito; 4) A harmonia da LEP com a CF; 5) A execução provisória da sentença condenatória recorrível na visão do STJ e do STF; 6) Referências bibliográficas.

\section{@ INTRODUÇÃO}

Dando continuidade ao nosso projeto de comentários aos principais temas da seara penal e em respeito aos caros operadores do Direito, cujas observações críticas têm nos ensinado mais e mais e enriquecido o debate, traçaremos aqui algumas linhas doutrinárias e jurisprudenciais sobre a execução provisória de sentença condenatória recorrível. Note que este estudo não se restringe à execução provisória da pena de prisão, mas a qualquer espécie de pena proferida em sede de condenação recorrível.

Sendo assim, salta-nos de imediato a pergunta: é possível em pleno avanço do Estado Democrático de Direito, inclusive numa época em que se intensificam os debates sobre democracia participativa, Constituição dirigente, enfim, tempos em que os valores jurídicos são teorizados com tanta ênfase em prol do estritamente humano, até mesmo na tentativa de reformatar nossa memória quanto às restrições indevidas aos direitos fundamentais no Estado de exceção que vivemos em tempos idos, conceber a execução de uma sentença condenatória antes de transitar em julgado?

Bem, para que o leitor saiba desde já o curso que tomará este ensaio, deixamos de logo expressa nossa resposta à indagação acima: não, não concebemos, perante 
os valores protegidos constitucionalmente nesta etapa da história jurídica do País, que alguém possa ser punido em razão de decisão judicial ainda passível de reforma.

Temos que não seja justo restringir-se a liberdade de alguém, valor extremamente caro ao sistema de garantias constitucionais e verdadeira pilastra da ordem jurídica vigente, ou executar qualquer tipo de pena contra alguém, quando nem mesmo a Justiça tem como verdade imutável uma condenação realizada tãosó por primeira instância. O próprio fundamento de existência das armas recursais - a falibilidade humana - ratifica nossa afirmação. Aliás, considera-se um truísmo a máxima: errar é humano. Enfim, verdade advinda da própria condição humana.

No entanto, neste instante, não é por caminho metajurídico que pretendemos expor nossas idéias, quem sabe em outro estudo, mas pela ótica do direito positivo, estudaremos a constitucionalidade e a legalidade da execução provisória da sentença condenatória recorrível.

Oportuno chamarmos a atenção do leitor para o fato de que se aguarda decisão do Plenário do STF sobre a execução provisória da pena privativa de liberdade (Reclamação 2391 MC/PR, Informativo n 334). Por outro lado, já há orientações do STF entendendo pela inadmissibilidade da execução provisória da sentença condenatória à pena restritiva de direitos. ${ }^{1}$

Analisemos, portanto, algumas premissas que nos levam a entender que sentença condenatória recorrível, seja qual for a pena, não pode ser executada provisoriamente.

\section{A Constituição Como Limite Ao Exercício do Poder do Estado}

O direito deve ser exercido em prol do homem. Jesus Cristo, certa feita, questionado pelos religiosos de sua época porque permitia que seus discípulos colhessem espigas no sábado, dia em que o judaísmo impunha proibição ao trabalho, afirmou, tendo em vista o estado de necessidade de seus seguidores naquele momento, que a lei foi feita para o homem e não o contrário. No entanto, conforme relata a história do direito, a prática nem sempre se aliou à teoria. Tanto que Geraldo Ataliba chega a dizer que o "Direito se ensina praticamente por obras mais que por palavras. Não que estas não sejam necessárias, mas só são fecundas - como a pregação evangélica - se secundadas por gestos” ${ }^{2}$.

O contraposto desse ideal deu-se, na história da humanidade, sempre pelo excesso no exercício do poder estatal. Aliás, como já foi dito, por outras palavras,

\footnotetext{
${ }^{1}$ HCs 84.741/RS, 85.289/SP, 84.104/DF, 84.087/RJ, 88.413/MG, 83.415/SP e 83.173/SP.

2 República e Constituição. São Paulo: Malheiros, 1998, p. 17.
} 
o poder traz consigo o germe do arbítrio. A deflagração do movimento constitucionalista (séc. XVIII) foi justamente a luta para por balizas ao pretenso poder ilimitado do monarca, frente aos direitos à liberdade e à propriedade. A partir da revolução francesa, a idéia é a Constituição como limite à atuação do Estado junto à sociedade. Dali em diante, o Estado é de direito.

Esse pressuposto histórico, que fazemos em brevíssima síntese, é de imprescindível importância a todo o entendimento do Direito, pois o paradigma hermenêutico agora é outro: toda norma jurídica deve ser criada, interpretada e executada em prol do novo titular do poder: o povo, ou, mutatis mutandis, na ótica do direito penal, o réu. A frase de Luís XIV (o Estado sou Eu) é hoje de inconcebível pronúncia por um governante, no Estado de Direito. O que ficou consagrado na Constituição brasileira de 1988, ao dispor que "todo poder emana do povo, que o exerce por meio de representantes eleitos ou diretamente, nos termos desta Constituição" (art. $1^{\circ}$ ).

Aliás, no que respeita ao tema prisão, o constituinte não poupou tinta para resguardar a dignidade do preso, pondo sempre a privação da liberdade como medida excepcional. Senão vejamos:

"LIV - ninguém será privado da liberdade ou de seus bens sem o devido processo legal”;

"LVII - ninguém será considerado culpado até o trânsito em julgado de sentença penal condenatória”;

"LX - a lei só poderá restringir a publicidade dos atos processuais quando a defesa da intimidade ou o interesse social o exigirem”; "LXI - ninguém será preso senão em flagrante delito ou por ordem escrita e fundamentada de autoridade judiciária competente, salvo nos casos de transgressão militar ou crime propriamente militar, definidos em lei”;

"LXII - a prisão de qualquer pessoa e o local onde se encontre serão comunicados imediatamente ao juiz competente e à família do preso ou à pessoa por ele indicada";

"LXIII - o preso será informado de seus direitos, entre os quais o de permanecer calado, sendo-lhe assegurada a assistência da família e de advogado";

"LXIV - o preso tem direito à identificação dos responsáveis por sua prisão ou por seu interrogatório policial”;

"LXV - a prisão ilegal será imediatamente relaxada pela autoridade judiciária”;

"LXVI - ninguém será levado à prisão ou nela mantido, quando a lei admitir a liberdade provisória, com ou sem fiança”; 
“LXVII - não haverá prisão civil por dívida, salvo a do responsável pelo inadimplemento voluntário e inescusável de obrigação alimentícia e a do depositário infiel”;

"LXVIII - conceder-se-á "habeas-corpus" sempre que alguém sofrer ou se achar ameaçado de sofrer violência ou coação em sua liberdade de locomoção, por ilegalidade ou abuso de poder;”.

Logo, qualquer interpretação que ponha como regra a restrição do exercício dos direitos fundamentais não goza de legitimidade na presente ordem jurídica constitucional. Por essa razão inicial, não concordamos quando determinadas decisões, como a proferida pelo STF no HC 80.174-9/SP, entre muitas outras, asseveram ser exceção o recurso em liberdade, sendo regra o recolhimento do condenado à prisão para ser admitida a apelação.

Repitamos mais uma vez: a restrição dos direitos fundamentais é medida de total excepcionalidade no Estado Democrático de Direito, que exige do legislador, do executor da orientação legal e do juiz, extrema cautela e rigor no exercício de seus trabalhos. Justamente por essa linha de interpretação é que ganha força a cautelaridade das prisões processuais.

\section{$\checkmark$ A Liberdade como Regra e a Prisão como Medida Excepcional: Pilastras do Estado Democrático de Direito}

Por uma razão cronológica, abordaremos inicialmente o que dispôs a lei, sobre a execução provisória da sentença condenatória. O Código de Processo Penal, surgido com o Decreto-lei 3.689 de 1941, momento em que vigiam no País e no mundo (guerra mundial) valores completamente diferentes dos de agora, traz algumas regras sobre a matéria. In verbis:

“Art. 393. São efeitos da sentença condenatória recorrível:

"I - ser o réu preso ou conservado na prisão, assim nas infrações inafiançáveis, como nas afiançáveis enquanto não prestar fiança;” (grifamos).

Mais adiante, a Lei $\mathrm{n}^{0}$ 5.941, de 22.11.1973, fez inserir no CPP a seguinte redação:

“Art. 594. O réu não poderá apelar sem recolher-se à prisão, ou prestar fiança, salvo se for primário e de bons antecedentes, assim reconhecido na sentença condenatória, ou condenado por crime de que se livre solto" (grifamos). 
Evidentemente, que tais normas processuais devem ser lidas a partir dos princípios e normas constitucionais. A Constituição é que deve ditar a interpretação dos referidos artigos, purificando-os dos valores da época de sua criação. Ademais, como se sabe, qualquer norma infraconstitucional somente permanecerá como vigente e aplicável no sistema se passar pelo crivo da Carta Constitucional.

Assim, os arts. 393 I, e 594 do CPP devem ser entendidos, principalmente, a partir das seguintes normas constitucionais:

"LVII - ninguém será considerado culpado até o trânsito em julgado de sentença penal condenatória”;

"LXVI - ninguém será levado à prisão ou nela mantido, quando a lei admitir a liberdade provisória, com ou sem fiança;"

Portanto, a priori, ser tido como culpado antes do trânsito em julgado da sentença condenatória não significa obrigatoriamente ser preso, nem ser levado à prisão quer dizer, necessariamente, ser condenado. Isso porque defendemos que a pena somente poderá ser executada quando a sentença condenatória não puder mais ser reformada, tendo em vista o princípio da presunção de inocência, e que a única prisão permitida, antes do trânsito em julgado da sentença, é a prisão de caráter processual (preventiva, provisória, em flagrante, decorrente da decisão de pronúncia e em virtude de sentença condenatória recorrível) apoiada nos requisitos da medida cautelar, o fumus boni iuris e o periculum in mora. Fora esta prisão, o condenado pode apelar em liberdade, direito que independe de seu histórico criminal.

Conforme a Súmula $n^{\circ} 9$ do STJ, "a exigência da prisão provisória, para apelar, não ofende a garantia constitucional da presunção de inocência”.

Só a título de esclarecimento, da legislação processual penal se pode inferir - e assim o faz toda a doutrina nacional - que há dois tipos de prisão: I) a prisão penal (trata-se de medida penal destinada à satisfação da pretensão executória do Estado); II) a prisão processual (trata-se de prisão de natureza puramente processual, imposta com finalidade cautelar, destinada a assegurar o bom desempenho da investigação criminal, do processo penal ou da execução da pena, ou ainda a impedir que, solto, o sujeito continue praticando delitos). A prisão processual busca fundamento de existência no periculum in mora e no fumus bonis iuris ${ }^{3}$.

Conforme Haroldo Serrano de Andrade:

“A fumaça do bom direito assenta-se nas fundadas suspeitas de autoria/participação do réu em fato delituoso, além da comprovada

${ }^{3}$ CAPEZ, Fernando. Curso de processo penal. 13a edição. São Paulo: Saraiva, 2006, pp. 244-45. 
existência material do crime. Aqui, a efetiva plausibilidade do pedido acusatório é a "tônica”, a revelar a preocupação do ordenamento processual com a tutela da aparência ou com aquilo que se convencionou chamar de juízo de verossimilhança; o perigo da demora escora-se no binômio da necessidade-urgência, de modo que a inflição da medida deve mostrar-se como expediente absolutamente inadiável (urgente) e indispensável à preservação da ordem jurídica (necessário). Em síntese, a prisão processual só será materialmente constitucional, se for necessária e urgente para a garantia da paz social e fundada num mínimo de prova sobre a autoria de crime. Do contrário, ela não será admissível em nenhuma das suas formas, razão por que, se decretada, deverá ser prontamente relaxada pelo juiz (art. $\left.5^{\circ}, \mathrm{LXV}\right){ }^{\prime}{ }^{4}$.

Interessante é que Capez sugere também, para a prisão processual, o título de prisão provisória, o que nos leva a pensar que o CPP apenas falou em liberdade provisória, que talvez seja justificável para sua época (1941), mas para os dias atuais, conforme falamos, a garantia dos direitos fundamentais é regra e não exceção. Logo, à luz dos valores constitucionais em vigor, se a prisão pode ser provisória, considera-se uma agressão aos direitos fundamentais qualificar a liberdade de provisória. Isso porque - ressalte-se - a liberdade é a regra, e a prisão é medida excepcional. Eugênio Pacelli, autor que vislumbrou tamanha impropriedade, escreveu:

“É por isso que estamos a afirmar que o sistema prisional do Código de Processo Penal de 1941 foi elaborado e construído a partir de um juízo de antecipação de culpabilidade - aqui referida no sentido latu, de responsabilidade penal - na medida em que a fundamentação da custória (ou prisão) refere-se à lei e não a uma razão cautelar específica.

“Com a Constituição Federal de 1988, duas conseqüências imediatas se fizeram sentir no âmago do sistema prisional, a saber: a) a instituição de um princípio afirmativo da situação de inocência de todo aquele que estiver submetido à persecução penal; b) a garantia de que toda prisão seja efetivamente fundamentada e por ordem escrita de autoridade judiciária competente.

${ }^{4}$ Prisão decorrente de condenação criminal recorrível: breves considerações. Jus Navigandi, Teresina, ano 9, n. 802, 13 set. 2005. Disponível em: <http://jus2.uol.com.br/doutrina/texto.asp?id=7284>. 
“A mudança é muito mais radical do que pode parecer a um primeiro momento e superficial exame”.

"E assim é porque o reconhecimento da situação jurídica de inocente (art. $5^{\circ}$, LVII) impõe a necessidade de fundamentação judicial para toda e qualquer privação da liberdade, posto que só o Judiciário poderá determinar a prisão de um inocente. E, mais, que essa fundamentação seja construída em bases cautelares, isto é, que a prisão seja decretação como acautelamento dos interesses da jurisdição penal, com a marca da indispensabilidade e da necessidade da medida." ${ }^{5}$ (Grifamos).

Corroborando o exposto em linhas pretéritas, isto é, de que a partir das premissas jurídicas do Estado de Direito toda compreensão de princípios e normas constitucionais deve ser realizada em prol do povo (réu, contribuinte etc) e não mais do monarca, e, no mesmo passo, alicerçando o atributo da cautelaridade da prisão provisória é que surge com a Ordem Constitucional de 1988 o princípio da presunção de inocência, ou como acharemos nos manuais de processo penal: princípio da inocência, estado de inocência, princípio da não-culpabilidade ou direito fundamental ao estado de inocência. ${ }^{6}$

Várias legislações seguem nesse sentido os passos do legislador constituinte (art. 5, LVII), trazendo o princípio da inocência, como por exemplo: a Declaração dos Direitos do Homem e do Cidadão de 1789 (art. $9^{\circ}$ ), a Declaração Americana de Direitos e Deveres (art. 26), a Declaração Universal dos Direitos Humanos (art. 11) e a Convenção Americana sobre Direitos Humanos (Pacto São José da Costa Rica, art. $8^{\circ}$ ), a qual o Brasil já aderiu em 1992. Não se pode olvidar que o estado de inocência, como qualquer outro princípio constitucional, goza apenas de presunção relativa, não impedindo que alguém seja indiciado ou preso provisoriamente, desde que se fundamentem os pressupostos cautelares da medida. O que não pode tomar a exceção pela regra.

Inclusive não vemos qualquer obstáculo - mas pelo contrário, total harmonia com os vetores da Carta Política - para excepcionar-se a presunção de inocência e dar cumprimento provisório à execução da pena tão-somente quando em benefício do réu, orientação esta já consolidada pelo STF na Súmula $n^{\circ} 716$ : "Admite-se a progressão de regime de cumprimento de pena ou a aplicação imediata de regime menos severo nela determinada, antes do trânsito em julgado da sentença condenatória”.

\footnotetext{
${ }^{5}$ Curso de processo penal. $3^{\text {a }}$ edição. Belo Horizonte: DelRey, 2004, p. 490.

${ }^{6}$ MIRABETE, Julio Fabbrini. Processo penal. 16 edição. Revista e atualizada por Renato N. Fabbrini. São Paulo: ATLAS, 2004, p. 45.
} 
Enfim, nomenclaturas à parte, importa saber que ninguém pode ser punido, perante o moderno sistema constitucional-penal, se ainda não se tornou imutável a sentença condenatória. Enquanto o sistema dispensar ao réu a possibilidade de recurso, não poderá ser considerado, na estrita acepção do termo, culpado, sendo privado de sua liberdade, salvo as situações excepcionais das prisões cautelares.

\section{$\checkmark$ A Harmonia da LeP COM a CF}

Conquanto de 1984, mas em total sintonia com o princípio do estado de inocência, vê-se a Lei de Execuções Penais. Por isso, trazemo-na em tópico à parte, ainda que em reforço de sua aplicação. A Lei nº 7.210, inclusive, tem sido fonte legislativa dos avanços das orientações do STF quanto à matéria em exame, referida demasiadamente no julgamento de vários habeas corpus.

Assim dispõe a LEP sobre a execução da sentença condenatória:

“Art. 105”. Transitando em julgado a sentença que aplicar pena privativa de liberdade, se o réu estiver ou vier a ser preso, o Juiz ordenará a expedição de guia de recolhimento para a execução. “Art. 107. Ninguém será recolhido, para cumprimento de pena privativa de liberdade, sem a guia expedida pela autoridade judiciária. “Art. 147. Transitada em julgado a sentença que aplicou a pena restritiva de direitos, o Juiz da execução, de ofício ou a requerimento do Ministério Público, promoverá a execução, podendo, para tanto, requisitar, quando necessário, a colaboração de entidades públicas ou solicitá-la a particulares.”

Notem que a letra do art. 147 da LEP é clara ao dispor que somente será aplicada a pena restritiva de direitos após o trânsito em julgado da sentença. Com base nesse dispositivo e na presunção de inocência, o STF tem deferido vários habeas corpus (HCs 84.741/RS, 85.289/SP, 84.104/DF, 84.087/RJ, 88.413/MG, 83.415/SP e 83.173/SP).

Não obstante, nos demais artigos também podemos extrair conclusões quanto à proibição do cumprimento provisório da sentença quando a pena for privativa de liberdade. Isso porque, conforme os arts. 105 e 107, o condenado não poderá ser recolhido à prisão sem que o juiz expeça a guia de recolhimento. E a guia de recolhimento, como diz o art. 105, somente poderá ser expedida após o trânsito em julgado da sentença. Logo, tanto a pena restritiva de direitos como a pena privativa de liberdade somente poderão ser executadas após o trânsito em julgado da sentença.

O STF, por sua $2^{\mathrm{a}}$ Turma, deixou expresso na ementa do HC 85.886/RJ, do ano de 2005, que não há norma expressa que estabeleça ser o trânsito em julgado 
condição para o início da execução de condenação. Todavia, ainda que se questione a interpretação que acabamos de dar aos arts. 105 e 107 da LEP, não é razoável que para o cumprimento da pena restritiva de direitos, onde não há prisão, aguardese obrigatoriamente o trânsito em julgado da sentença condenatória, mas para a pena privativa de liberdade - liberdade como valor-mor do Estado de Direito e a prisão como exceção - não seja necessário essa premissa processual. No mínimo, caberia aqui o mecanismo integrativo da analogia in bonam partem, como solução sugerida àqueles que entendem que o sistema jurídico não traz norma expressa quando o assunto é cumprimento de pena privativa de liberdade antes de transitar em julgado a sentença condenatória.

\section{A Execução Provisória da Sentença CONDENATÓRIA RECORRÍVEL NA VISÃo Do STJ E DO STF}

Até há pouco tempo, a jurisprudência de nossos Tribunais Superiores apresentava orientações que, a nosso viso, destoavam por completo das premissas jurídicas do Estado moderno. Defendiam a prisão tão-só como conseqüência automática da sentença condenatória recorrível. Como o exemplo citado no início deste texto, acórdão do STF do ano de 2000, afirmou ser exceção o recurso em liberdade, sendo regra o recolhimento do condenado à prisão para ser admitida a apelação (HC nº 80.174-9/SP, Rel. Min. Maurício Corrêa).

O STJ, por sua vez, abandonando uma linha de interpretação mais progressista e em sintonia com os princípios constitucionais, em junho de 2002, por sua $3^{\text {a }}$ Seção, retroagiu na história de seus julgados para firmar a seguinte orientação:

“Os recursos para os Tribunais Superiores (STF e STJ), ex vi art. $27 \S 2^{\circ}$ da Lei $n^{\circ}$ 8.038D 90, em regra, só tem efeito devolutivo, sendo legítima a execução provisória do julgado condenatório, com expedição, se for o caso, de mandado de prisão (Precedentes do Pretório Excelso e do STJ). A eventual limitação, fixada em primeiro grau, quanto à expedição do mandado de prisão, não vincula o tribunal de segundo grau (Precedentes do Pretório Excelso)" (HC 13378D SP, Rel. pD acórdão Min. Felix Fischer, DJ de 26.03.2001). Ordem denegada (STJ, $3^{\text {a }}$ Seção, $\underline{\text { HC n }{ }^{0} \text { 19.406/ }}$ PR, rel. Min. José Arnaldo da Fonseca)

Ressalte-se, contudo, que o STF vem avançando, paulatinamente, em uma interpretação mais afinada com os valores constitucionais. Em vários habeas corpus, do ano de 2004 até o presente momento, não raras vezes, o Tribunal tem 
concedido liberdade a réus condenados a pena privativa de liberdade e logo convertida em pena restritiva de direitos ou somente condenados a pena restritiva de direitos (HCs 84.741/RS, 85.289/SP, 84.104/DF, 84.087/RJ, 88.413/MG, 83.415/SP, 83.173/SP 84.677/RS, 85.886/RJ e 83.484).

Há que aguardarmos, portanto, o desfecho do julgamento de mérito da Reclamação 2.391-5/PR (Info. 334), em que será enfrentado diretamente a constitucionalidade da execução provisória de pena privativa de liberdade, antes do trânsito em julgado da sentença. Fiquemos, para finalizar, com o voto do Min. Cezar Peluso, já prolatado nos autos da reclamação referida e transcrito no HC 88.413-0/MG, em que interpreta o inc. LVII do art. $5^{\circ}$ da CF:

“Parece-me óbvio que essa disposição constitucional não é, como não o é norma constitucional alguma, mera recomendação, nem tomada teórica de posição do constituinte a respeito da natureza da condição processual do réu; ela não tem menos óbvio sentido prático. Embora alguns vejam, em tal norma, uma suposta presunção de inocência, parece-me lícito abstrair indagação a esse respeito, no sentido de saber se hospeda, ou não, presunção de inocência. Há autores, sobretudo na Itália, que a propósito de regra análoga sustentam não conter presunção alguma, nem de inocência, nem de culpabilidade, senão e apenas enunciado normativo de garantia contra possibilidade de a lei ou decisão judicial impor ao réu, antes do trânsito em julgado de sentença penal condenatória, qualquer sanção ou conseqüência jurídica gravosa que dependa dessa condição constitucional, ou seja, do trânsito em julgado de sentença condenatória. Em outras palavras, independente de saber se contém, ou não, alcance de presunção - pode-se até dizer que a presunção de inocência é só uma das decorrências ou consectários dessa garantia, projetando-se como tal, por exemplo, na distribuição do ônus da prova no processo, o certo é que essa cláusula garante ao réu, em causa criminal, não sofrer, até o trânsito em julgado da sentença, nenhuma sanção ou conseqüência jurídica danosa, cuja justificação normativa dependa do trânsito em julgado de sentença condenatória, que é o juízo definitivo de culpabilidade.

Temos, pois, aqui, o seguinte dilema, já posto pelo Ministro SEPÚLVEDA PERTENCE: tirando-se as hipóteses de prisão em flagrante - a cujo respeito como modalidade de prisão cautelar, que é, não quero discorrer aqui, bastando estar prevista na Constituição - e de prisão preventiva, cuja finalidade básica é a tutela do processo, a possibilidade de alguém ser ou manter-se preso nos termos de ambas as normas invocadas na sentença não 
vejo como qualificar-se senão como hipótese típica de execução provisória de sentença penal (recorrível) e que por isso mesmo ofende de modo direto a garantia do inciso LVII do art. 5o da Constituição da República, porque se está impondo àquele que, na forma da mesma Constituição, ainda não foi considerado culpado por sentença transitada em julgado, a mais grave das sanções, que é a privação de sua liberdade.

Parece-me que, além disso - como já salientado pelos Ministros MARCO AURÉLIO e SEPÚLVEDA PERTENCE -, o que acentua a gravidade da interpretação da sentença é que as leis tratem de maneira penosamente invertida e desigual bens jurídicos que estão em posições hierárquicas distantes, ou seja, a lei subalterna não admite, na execução civil provisória, a qual tem só efeitos de caráter patrimonial e quase sempre reversíveis, a prática de atos de adjudicação ou de qualquer outra forma de alienação, ao passo que as duas normas penais aplicadas pela sentença permitiriam a imposição da sanção extrema e gravíssima da privação da liberdade, a qual é irreversível pela razão manifesta de que não há maneira de o sistema jurídica repará-la sequer mediante o expediente subrogatório da indenização (que aliás, não se sabe quando é paga). Esse tratamento normativo desigual, que castiga o réu com perda injusta e irreparável da liberdade física, agride o princípio da proporcionalidade, como variável da razoabilidade. Creio inconcebível que o sistema jurídico tolere essa incoerência de regulamentação desproporcional de conseqüências sancionatórias para valores jurídicos absolutamente díspares, atribuindo prudente proteção a bem jurídico que, diria, não é o mais valioso da vida, o patrimônio, e, na esfera penal, negando-o à liberdade do cidadão! Isso, para mim, ofende frontalmente, além da cláusula constitucional específica (art. 5o, LVII), o princípio da proporcionalidade, que veda toda sanção injustificável quando comparada com conseqüência prevista para hipótese mais grave em abstrato.

Considero, também, absurdo não menor que se possa extrair do preceito constitucional, por exemplo, a conseqüência - como já lembrado, na Turma, pelo Ministro SEPÚLVEDA PERTENCE de que estaria proibido lançar, antes do trânsito em julgado da sentença, o nome do réu no rol dos culpados, como se esta fosse a coisa mais importante do sistema jurídico. Como observou S. Exa., nunca se viu ou soube que alguém consultasse alguma vez tal livro! Seria esse, outro tipo gritante de desproporcionalidade: sustentar a 
impossibilidade de manter o nome do réu no rol dos culpados, mas permitir que ele permaneça preso até que sobrevenha julgamento definitivo, o qual bem pode declará-lo inocente! "Nada haveria de razoável nessa desequilibrada ponderação normativa que de igual modo subverteria a escala de valores emergentes da Constituição”.

\section{X) ReferênCias Bibliográficas}

ATALIBA, Geraldo. República e Constituição. São Paulo: Malheiros, 1998.

ANDRADE, Haroldo Serrano de. Prisão decorrente de condenação criminal recorrível: breves considerações. Jus Navigandi, Teresina, ano 9, n. 802, 13 set. 2005. Disponível em: <http://jus2.uol.com.br/doutrina/texto.asp?id=7284>.

FERNANDO, Capez. Curso de Processo Penal. 13a ed. São Paulo: Saraiva, 2006

OLIVEIRA, Eugenio Pacelli de. Curso de Processo Penal. $3^{\text {a }}$ ed. Belo Horizonte: DelRey, 2004.

MIRABETE, Julio Fabbrini. Processo Penal. $16^{\text {a }}$ ed. Revista e atualizada por Renato N. Fabbrini. São Paulo: Atlas, 2004.

\section{Provisory ENFORCEMENT OF JUDICIAL VERDICT SUBJECT TO APPEAL}

Abstract: This text argues initially that freedom is the rule, according to Brazilian law. Consequently, incarceration is the exception and must be regarded with full caution. And even more when the judicial verdict has not yet reached its full validity, in order to be enforced. The text concludes that it is still awaited the final manifestation from Brazilian highest courts whether it is constitutional or not.

Keywords: Constitution. Judicial verdict. Appeal. Incarceration. 